\title{
Escipión Emiliano, Polibio y Demetrio I Sóter
}

\author{
Scipio Aemilianus, Polybius, and Demetrius I Soter
}

Denis Álvarez Pérez-SostoA*

\begin{abstract}
RESUMEN
Este artículo analiza los posibles vínculos y lazos de amistad surgidos entre el noble romano Escipión Emiliano, el historiador heleno Polibio y el joven príncipe sirio Demetrio I Sóter. La relación entre los tres personajes parte de la desaparición del reino macedónico y la llegada de Polibio a Roma, ciudad en la que establecerá trato con Escipión Emiliano, su principal valedor y protector, y con Demetrio, a la sazón rehén en Roma.
\end{abstract}

PALABRAS CLAVE:

Rehenes, amistad, Escipión Emiliano, Polibio, Demetrio.

\begin{abstract}
This article analyses the possible bonds of friendship between the Roman nobleman Scipio Aemilianus, the Greek historian Polybius, and the young prince Demetrius I Soter from Syria. This relation starts after the disappearance of the Macedonic kingdom and Polybius's arrival to Rome, where the historian will establish contact with Scipio Aemilianus, his main defender and protector, and with Demetrius, at that time hostage in Rome.
\end{abstract}

KEYWORDS:

Hostages, friendship, Scipio Aemilianus, Polybius, Demetrius.

\section{INTRODUCCIÓN}

Tanto en el Mundo Antiguo como hoy en día, un concepto como el de la amistad y el de las relaciones sociales está abierto a todo tipo de interpretaciones. Con frecuencia los historiadores contemporáneos tienden a aplicar nociones o conceptos modernos a contextos en los que posiblemente la visión fuera diferente.

* Departamento de Estudios Clásicos, Universidad Pública del País Vasco (Paseo de las Universidades, 5. 01006 Vitoria). E-mail: denis.alvarez@ehu.es.

Artículo basado en la comunicación leída el 20 de Mayo de 2008, en la VII edición del Encuentro de Jóvenes Investigadores de Historia Antigua de la Universidad Complutense de Madrid. 
Ciertamente, la mayor dificultad estriba precisamente en este aspecto, el tratar de no hacer uso de una interpretación excesivamente actual de unos sucesos en los que la concepción de la sociedad, y por consiguiente, en el caso que nos ocupa, de la amistad difiere de la nuestra.

A este respecto conviene traer a colación la entrada que el Diccionario de la Real Academia de la Lengua Española ofrece para el sustantivo 'amistad': «Afecto personal, puro y desinteresado, ordinariamente recíproco, que nace y se fortalece con el trato»; y también «pacto amistoso entre dos o más personas». Creo que en estas circunstancias, y especialmente siguiendo la segunda acepción, es posible establecer el tipo de relación y, en su caso, el grado de amistad que unía a tres personajes tan dispares como son el noble romano Escipión Emiliano, también conocido como Escipión Africano Minor, al historiador heleno Polibio y al príncipe y futuro rey de Siria Demetrio I Sóter.

La III Guerra Macedónica que finaliza en el año 168 con la célebre batalla de Pidna y que va a suponer la desaparición de la monarquía macedónica es el factor principal que va a permitir el encuentro en Roma de los tres personajes citados. El año siguiente, como circunstancia directamente derivada de la derrota de Perseo, rey de Macedonia, la Liga Aquea se ve forzada a entregar a 1.000 de sus conciudadanos por haber, supuestamente, apoyado la causa macedónica. Entre ellos se encuentra Polibio, quien de esta forma pasa a formar parte del numeroso y variado contingente de rehenes diseminados en Roma y en las ciudades italianas, fruto de las conquistas llevadas a cabo por los romanos a lo largo de la primera mitad del siglo II a.C.

Como consecuencia directa de estos acontecimientos, Polibio va a entrar en contacto con la aristocracia romana, a través de la figura de Escipión Emiliano, y con uno de los rehenes de mayor relevancia confinados en Roma en el momento de la deportación del historiador de Megalópolis, el futuro Demetrio I de Siria. Con Polibio como nexo de unión, surge entre los tres una relación que, teniendo en cuenta el devenir de los acontecimientos -especialmente la situación de Demetrio-, es necesario entender como algo más que un simple contacto entre vencedores y vencidos, o entre iguales, en el caso de Polibio y Demetrio.

\section{DRAMATIS PERSONAE}

El concepto de la amistad ya fue estudiado por Cicerón, uno de los autores clásicos más prolíficos. En el famoso tratado sobre la amistad conocido como Laelius o de Amicitia, el orador de Arpino indica que ita contracta est et adducta in angustam, ut omnis caritas aut inter duos aut inter paucos iungeretur (Cic. Lael. 20) ${ }^{1}$. En el caso que nos atañe, la definición de Cicerón se ajusta a la perfección. La amistad queda reducida a un pequeño círculo formado por tres personas.

1 «De tal manera esta cosa fue contraída y reducida a un círculo tan estrecho, que todo afecto se enlaza entre dos o entre pocos». 


\subsection{Escipión Emiliano}

Publio Cornelio Escipión Emiliano, o Escipión Africano Minor, es sin duda alguna una de las figuras más destacables de la segunda mitad del siglo II. Conviene recordar que estaba ligado tanto por nacimiento como por adopción a tres de las familias más ilustres de la República. En primer lugar, era uno de los cuatro hijos de Emilio Paulo, el conquistador de Macedonia y causante indirecto de la llegada de Polibio a Roma, y por adopción pasó a integrarse en la gens Cornelia. Pero además estaba relacionado con la gens Fabia puesto que su hermano mayor fue adoptado por Quinto Fabio Máximo.

Además de sus orígenes, es necesario recalcar que Escipión Emiliano obtuvo los apelativos de Africanus Minor y Numantinus por haber coronado con éxito la III Guerra Púnica y la conquista de Numancia, momentos en los que al parecer Polibio se encontró presente acompañando a su amigo y protector.

\subsection{Polibio}

Tanto Polibio como su padre Licortas eran partidarios de Filopemén, defensor de la independencia de la Liga Aquea frente a la interferencia romana. La actitud de la Liga Aquea durante el conflicto entre Roma y Perseo no fue la deseada por los romanos. Al parecer, y según relata el propio historiador, la Liga prometió el envío de ayuda al legado romano Q. Marcio Filipo, pero Polibio contuvo dicho envío en tanto en cuanto la victoria romana no fuera clara y no pudiera faltar a la promesa dada (Polyb. 28.12).

Tras la victoria de Emilio Paulo en Pidna, Roma favoreció lógicamente a quienes habían contribuido a la misma. Los miembros de esta facción, rival del grupo en el que se encontraba Polibio, tenía como máximo exponente a Calícrates, por quien el historiador de Megálopolis no esconde su profundo rencor. Calícratres, por su parte, no perdió la ocasión de acusar a cuantos pudo de haber ayudado a Perseo, por lo que un nutrido grupo de griegos, entre ellos un contingente formado por 1.000 aqueos, fue deportado a Roma sin haber sido objeto de ningún juicio ni como consecuencia de las cláusulas contenidas en ningún tratado (Polyb. 30.32.112, 31.23.5, 32.6.4; Paus. 7.10.8ss.).

Es cierto que ninguna de las fuentes los define como obses u hómeros, términos que con mayor frecuencia evocan la figura del rehén, y que tampoco servían como garantes de un acuerdo o tratado. De hecho, tanto Polibio como Plutarco se refieren a los aqueos como «los residentes en Roma» (Polyb. 32.6.4), «los detenidos en Roma» (Polyb. 31.23.5) o «los exiliados» (Polyb. 35.6.1; Plut. Cat. 9.2-3). Cicerón llega incluso a llamar noster hospes a Polibio (Cic. Rep. 4.3.3). Aún así, parece evidente que cumplían precisamente la función de rehenes, no como avales de un acuerdo firme y valedero establecido entre Roma y la Liga Aquea, sino como elemento de presión a la hora de poder garantizar la correcta predisposición de los componentes del grupo opositor a Calícrates. Por desgracia, los autores gre- 
co-latinos no ofrecen apenas información acerca de la suerte corrida por los aqueos. Polibio indica que fueron distribuidos en varias ciudades de Italia (Polyb. 31.23.5), mientras que Pausanias sitúa su localización, de forma genérica, en Etruria (Paus. 7.10.11).

Una de las pocas excepciones fue precisamente la del historiador de Megálopolis. Al parecer, la intercesión directa de los hijos de Emilio Paulo, Escipión Emiliano y Fabio Máximo Emiliano, condicionaron la permanencia de Polibio en la capital gracias a los lazos de amistad forjados entre ellos. El propio historiador se

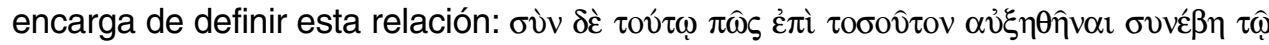

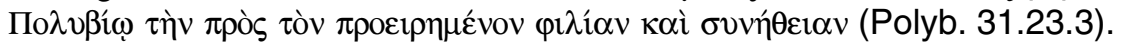

\subsection{Demetrio / Sóter}

En el proceso de expansión oriental, Roma se enfrentó con el rey Antíoco III de Siria. Tras varios años de confrontaciones, la victoria romana supuso la formalización de un tratado entre ambas potencias, un acuerdo que se efectuó en dos fases. Un primer acercamiento se llevó a cabo en el año 189 tras la derrota de Antíoco en Magnesia a manos de Lucio y Publio Cornelio Escipión. Posteriormente se produjo la ratificación definitiva, conocida como el tratado de Apamea, efectuada en el año 188 (Holleaux 1954: 199 ss.; Will 1967: 152 ss.; Paltiel 1979: 30-41).

Según las pautas habituales contempladas en los convenios establecidos entre Roma y sus enemigos, la Paz de Apamea incluía la imposición de ciertas obligaciones a cumplir por el derrotado. Generalmente, estas disposiciones abarcaban cláusulas económicas -imposición de un tributo o sanción a pagar en determinado período de tiempo-, militares —entrega de armamento y establecimiento de un cupo para el mantenimiento de un ejército en activo-, territoriales - la cesión de parte del territorio-, y, por último, personales. Las cláusulas personales son aquéllas en las que se reclama la entrega de ciertos grupos de personas, básicamente los desertores o tránsfugas, los prisioneros de guerra caídos en manos del enemigo, y un número variable de rehenes con los que asegurar el correcto cumplimiento del acuerdo. En el tratado de Apamea se especificaba la obligatoriedad de entregar 20 rehenes elegidos por los romanos. Debían tener una edad comprendida entre los 18 y los 45 años, serían renovados cada tres años y en el grupo se incluiría obligatoriamente al hijo del rey, el futuro Antíoco IV Epífanes (Polyb. 21.42.22; Liv. 28.38.15; Eutr. 4.4.3; Just. 31.8.8). El único rehén que quedaba excluido del proceso de renovación trienal y debía, por tanto, permanecer en Roma era el hijo del rey (App. Syr. 39; Zonar. 9.20).

Tras la muerte de Antíoco III le sucedió en el trono Seleuco IV, su hijo mayor y hermano a la sazón de Antíoco IV, quien aún permanecía en Roma en calidad de rehén. Ante la nueva situación política, el nuevo monarca creyó conveniente que su hermano menor regresara a Siria entregando para ello y a modo de relevo a su propio hijo, el futuro Demetrio I Sóter, aunque este reemplazo no debe ser contemplado dentro de las cláusulas contenidas en el tratado de Apamea (App. Syr. 
45). El momento preciso del intercambio debe situarse hacia el año 175. Una vez más los autores clásicos no detallan este episodio como sería de desear y por ello esta cuestión sigue siendo fuente de debate aún hoy en día (Aymard 1953; 1955; Walbank 1957-1979 III: 478; Mørkholm 1966: 38-50; Moscovich 1983: 303; Braund 1984: 176; Elbern 1990: 115; Allen 2006: 15).

Lo cierto es que Demetrio, que había nacido en el año 187, llegó a Roma en sustitución de su tío con unos 12 años. Es precisamente durante su prolongada estancia en suelo italiano que entrará en contacto con los demás rehenes confinados en la capital y con parte de la clase dirigente de la República romana entablando, al parecer, una especial relación con Polibio y, probablemente, a través de éste con Escipión Emiliano.

\section{ROMAE}

En general, poco es sabido de la situación de los rehenes una vez que llegaban a su lugar de confinamiento (Walker 1980: 95 ss.; Pavón Torrejón 2003; Allen 2006: 15 ss.; Álvarez Pérez-Sostoa 2009: 151 ss.). De los escasos episodios de los que hay noticia parece desprenderse un tipo de vida en la que no existían demasiadas limitaciones ni restricciones. Hay incluso quien ha definido la vida de ciertos rehenes como de opulenta (Matthews 1989: 39). Perseo, por ejemplo, aún siendo un captivus o aichmálotos, en definitiva, un prisionero de guerra y no un rehén, fue confinado en "custodia libre ${ }^{2}$, aunque no tengamos constancia de las verdaderas condiciones que rodeaban este tipo de detención.

Mientras que los rehenes que quedaban en manos de los enemigos de Roma siempre se quejan de las vejaciones y de los maltratos sufridos, más aún si se trata de mujeres y niños, los autores clásicos muestran un cuadro completamente diferente en el caso romano. Parece evidente, por tanto, que los que llegaban a la Urbs o a las diversas ciudades italianas no estaban sometidos a las mismas condiciones degradantes, aunque es posible que todo se deba a una visión interesada ofrecida por nuestras fuentes queriendo marcar una clara línea de distinción entre la actividad romana y la del resto (Allen 2006: 91).

El caso de Demetrio es extremadamente llamativo. Tras la muerte de Antíoco IV, a quien él había sustituido en Roma como rehén, quedó como heredero un niño de corta edad que accedió al trono con el nombre de Antíoco V. Demetrio consideraba que su presencia en Roma era ya innecesaria por lo que se dirigió repetidas veces al Senado para pedir que lo liberaran, incidiendo en que Roma era para él su hogar, que los hijos de los senadores eran como hermanos y los propios senadores como padres (Polyb. 31.2.6-7; 11.9; App. Syr. 46; Zonar. 9.25). Creyendo además ser el legítimo heredero al trono, sus deseos de libertad aumentaron, razón por la cual sus esfuerzos se intensificaron, no tanto por tratar de recuperar el

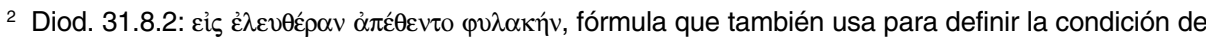
Sífax (Diod. 27.6.1). 
trono paterno, sino por el hecho de que su presencia en Roma era ya del todo innecesaria.

Tras las constantes negativas del Senado, no le quedó más remedio que planear su fuga y tratar de volver por sus propios medios a Siria para disputarle el trono a su primo, acción que culminó con éxito en el año 162, cuando ya llevaba 15 años confinado en calidad de rehén. Para ello, y tras planear cuidadosamente los pasos a seguir, justificó su ausencia de Roma bajo el pretexto de que estaba cazando en las afueras de la Urbs (Polyb. 31.14-15). Ciertamente es posible que al tratarse de un príncipe tuviera mayor facilidad que otros detenidos, no en vano tenía acceso a los gobernantes de la República, por lo que al menos durante varios días su ausencia no llamaría demasiado la atención. Una vez más, el tratado sobre la amistad de Cicerón nos da pie para poder comprender los siguientes eventos: Atque in omni re considerandum est et quid postules ab amico et quid patiare a te impetrari (Cic. Lael. 76) ${ }^{3}$.

El contacto entre los diversos personajes retenidos en Roma es evidente dada la amistad que entablaron Demetrio y Polibio. Esta se pudo cimentar gracias a actividades lúdicas, tales como la caza, de la que ambos rehenes disfrutaron y compartieron durante su estancia en Roma (Polyb. 31.14.2-3; 29.8). Los frutos de esta amistad se plasmaron con mayor claridad en el momento de la huída de Demetrio, pues el propio Polibio se postula como uno de los que le ayudaron a elaborar sus planes (Polyb. 31.12). En este punto no se debería descartar el que hubieran contado con la inestimable ayuda de los Escipiones, a los que tan estrechamente estaba unido el historiador de Megálopolis (Volkmann 1925: 383394; Badian 1958: 108). Aunque la huída de Demetrio supuso un golpe a la autoridad romana y en un primer momento no se le reconoció como el legítimo soberano, la rápida consecución del trono hizo cambiar la actitud de Roma. No en vano, ambas posibilidades eran atractivas para Roma. Por una parte, un joven monarca que sería más fácil de controlar que un gobernante con sobrada y larga experiencia; por otro lado, un rehén que había vivido en Roma durante la mayor parte de su vida y que con toda seguridad había sido educado de forma que se sintiera más romano que perteneciente a la casa real siria.

Mientras Polibio contribuía a la huída del príncipe sirio, los rehenes aqueos seguían en Italia desconociendo en todo momento el futuro que les aguardaba. A pesar de todo, el historiador menciona al menos cuatro embajadas fallidas que abogaban por la libertad de los detenidos en los años 164, 159, 155 y 153 (Polyb. 30.2.1-9; 32.3.14-17; 33.1.3; 3. 1-2; 33.14). Resulta significativa la insistencia de los aqueos por tratar de recuperar a sus conciudadanos teniendo en cuenta que en ningún momento actuaban como garantes de ningún acuerdo y que hasta cierto punto se encontraban en una especie de limbo jurídico, pues técnicamente no eran prisioneros de guerra ni rehenes, aunque de facto asumieran todas las características de estos últimos.

${ }^{3}$ «Y en toda ocasión debe considerarse tanto lo que se pide al amigo como lo que se permite que obtenga de nosotros». 
En el caso de Polibio, la amistad que lo unía con los Escipiones probablemente hizo que su estancia en Roma fuera bastante más agradable que la de otros muchos. Gracias a la mediación de Escipión Emiliano y con el visto bueno de Catón el Censor, en el año 150 el Senado concedió la libertad a los aqueos. Catón apoyó la petición de Escipión alegando que el Senado tenía cosas más importantes que discutir que el hecho de que unos viejos aqueos fueran conducidos a sus sepulturas por manos romanas o aqueas (Plut. Cat. 9.2). Al parecer, tras 16 años de confinamiento apenas quedaban 300 aqueos repartidos en Italia (Paus. 7.10.12). La decisión del Senado concedía la libertad a Polibio y la posibilidad de que éste regresara a su patria. Ciertamente, al poco de recobrar la libertad, Polibio parece mostrar atención por los acontecimientos que se desarrollan en Grecia, especialmente por aquéllos concernientes a los aqueos (Polyb. 38.3.8-13; 39.5), si bien su principal ámbito de estudio seguirá siendo el romano.

De todas formas, los lazos establecidos con Escipión Emiliano eran lo suficientemente sólidos para que siguiera unido a él. Durante su estancia como rehén en Roma parece haber visitado la Galia, Hispania y África (Polyb. 3.48.12; 10.11.4). Tras su liberación, durante la III Guerra Púnica, pudo incluso haber navegado más allá de las Columnas de Hércules en una embarcación que el propio Escipión le habría procurado (Plin. NH5.9), además de ser testigo de excepción de la caída y definitiva conquista de Cartago, por la que su querido amigo obtendría el cognomen de Africanus Minor (Polyb. 38.22.1-3). Por último, es posible que hubiera estado también en la conquista de Numancia, aunque este último evento no se pueda asegurar con toda rotundidad (Walbank 1957-1979 I: 382; 1972: 11).

\section{CONCLUSIONES}

Como conclusión quisiera evocar otro pasaje del Laelius de Cicerón: Namque hoc praestat amicitia propinquitati, quod ex propinquitate benevolentia tolli potest, ex amicitia non potest (Cic. Lael. 19) ${ }^{4}$. El orador se encarga de recordarnos que la amistad es superior al parentesco. Para ello incide en que, mientras del parentesco se pueden eliminar las trazas del cariño, de la amistad no. Esta afirmación abre las puertas, a mi entender, a la posibilidad de que la amistad se amplíe a círculos distintos al entorno familiar. Establece la formación de unos vínculos que nada tienen que ver en principio con el origen o el status de cada una de las personas. Por tanto, considero que lo expuesto hasta ahora demuestra de forma fehaciente la existencia de ciertos lazos de amistad entre los tres personajes estudiados en el presente trabajo.

Por una parte se establece una relación personal evidente entre Polibio y Demetrio. En verdad en el caso de Demetrio los intereses particulares pueden servir de acicate a la hora de entablar cierto grado de unión o acercamiento con Polibio,

4 «La amistad, en efecto, supera al parentesco en esto: en que el cariño puede eliminarse del parentesco, de la amistad no se puede». 
pero como señalaba Cicerón, siempre se debe tener en cuenta lo que se pide a un amigo y lo que se permite que éste obtenga de nosotros. En efecto, aunque distintos por derecho de nacimiento, sus orígenes quedan eclipsados una vez que pasan a manos romanas. El primero proviene de una oligarquía mientras el segundo es el príncipe de una de las monarquías helenísticas de Oriente. En Roma, en cambio, se trata de dos rehenes cuyo destino depende siempre de la voluntad de quien los retiene y tan sólo una vez que Demetrio consigue huir y el Senado decreta la liberación de los aqueos ambos vuelven a recuperar su respectivo status, aunque por supuesto la relación establecida durante la estancia en Roma seguiría existiendo. Demetrio consigue el ansiado trono paterno y Polibio, aún pudiendo regresar a Megálopolis, queda profundamente marcado por su estancia en Roma como es patente en su obra (Allen 2006: 201).

Por otra parte, frente a esta relación de tipo horizontal creo que así mismo se establece un vínculo en sentido vertical. Considero que este trato es claro entre Escipión Emiliano y Polibio. La posible participación de Escipión en la huída de Demetrio no está atestiguada por los autores greco-latinos, pero dada la proximidad existente entre Polibio y el noble romano no sería descabellado pensar que estuviera al corriente de la actuación de Demetrio. Es posible que no fuera partícipe directo en el plan del príncipe sirio, pero tal y como reza la segunda acepción del Diccionario de la Real Academia de la Lengua Española, un pacto amistoso entre dos o más personas sellaría la relación de estos tres personajes con un vínculo lo suficientemente estrecho como para poder referirse al mismo como amistad.

\section{BIBLIOGRAFÍA}

ALLEN, J. (2006), Hostages and Hostage-taking in the Roman Empire, Cambridge.

ÁLVAREZ PÉREZ-SOSTOA, D. (2009), «El confinamiento de los prisioneros de guerra y rehenes en la Roma republicana», Veleia 26, 151-169.

AYMARD, A. (1953), «Autour de l'avenement d'Antiochus IV», Historia 2, 49-73.

- (1955), «Du nouveau sur la chronologie des séleucides», REA 57, 102-122.

BADIAN, E. (1958), Foreign Clientelae (274-70 B.C.), Oxford.

BRAUND, D. (1984), Rome and the Friendly King, London.

ELBERN, S. (1990), "Geiseln in Rom», Athenaeum 78, 97-140.

HOHL, E. (1931), «Zu Polybios 31.12ff.», Hermes 66, 91-96.

HOLLEAUX, M. (1954), «Rome and Antiochus», CHA 8, 199-240.

LAQUEUR, R. (1930), «Die Flucht des Demetrius aus Rom», Hermes 65, 129-166.

MATTHEWS, J.F. (1989), «Hostages, philosophers, pilgrims, and the diffusion of ideas in the late Roman Mediterranean and Near East», en Clover, F. M. y Humphreys, R. S. eds., Tradition and Innovation in Late Antiquity, Wisconsin, 29-49.

MØRKHOLM, O. (1966), Antiochus IV of Syria, København.

MOSCOVICH, M.J. (1983), «Hostage princes and Roman imperialism in the second century BC», EMC 27.2, 297-309.

PALTIEL, E. (1979), «The treaty of Apamea and the later Seleucids», Antichthon 13, 30-41. - (1979), «Antiochos IV and Demetrios I of Syria», Antichthon 13, 42-47.

PAVÓN TORREJÓN, P. (2003), La Cárcel y el Encarcelamiento en el Mundo Romano, Anejos de $A E s p A 27$.

VOLKMANN, H. (1925), «Demetrios I und Alexander I von Syrien», Klio 19, 373-412. 
WALBANK, F. W. (1957-1979), A Historical Commentary on Polybius, 3 vols., Oxford. - (1972), Polybius, Berkeley.

WALKER, C. L. (1980), Hostages in Republican Rome, Cambridge.

WILL, E. (1967), Histoire Politique du Monde Hellénistique (323-30 av.J.C.), Nancy.

ZAMBELLI, M. (1960), «L'ascesa al trono di Antioco IV Epiphane di Siria», RFIC 99, 363-389. 